\title{
Methods and Design of the Baseline Survey of the Neurological Disorders in Salamanca (NEDISA) Cohort: A Population-Based Study in Central-Western Spain
}

\author{
Jesús Cacho ${ }^{a} \quad$ Julián Benito-León ${ }^{b, c}$ Elan D. Louis ${ }^{\mathrm{d}-\mathrm{g}}$ \\ on behalf of the NEDISA Study Group \\ ${ }^{a}$ Department of Neurology, Salamanca University Hospital, Salamanca, ${ }^{b}$ Department of Neurology, \\ University Hospital '12 de Octubre', Madrid, and 'Centro de Investigación Biomédica en Red sobre Enfermedades

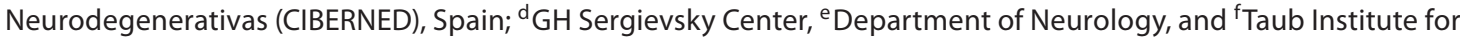 \\ Research on Alzheimer's Disease and the Aging Brain, College of Physicians and Surgeons, and ${ }^{9}$ Department of \\ Epidemiology, Mailman School of Public Health, Columbia University, New York, N.Y., USA
}

\section{Key Words}

Elderly · Epidemiology · Population-based survey

\begin{abstract}
Background: To describe the design of the baseline assessment of an epidemiological study of elderly persons living in Salamanca, central-western Spain: the Neurological Diseases in Salamanca (NEDISA) study. We assessed the epidemiology of stroke, cognitive disorders, essential tremor (ET), Parkinson's disease (PD) and restless legs syndrome. Methods: In phase 1 (February 1 to May 31, 2007), 4 neurologists and 2 trained general physicians examined and performed phlebotomy on all participants. In phase 2 (June 1, 2007, to June 1,2008 ), the participants were reexamined and had a complete neuropsychological assessment. Neuroimaging was performed in participants with cognitive disorders, ET and PD. Results: The registered study population consisted of 1,077 individuals, but 45 people were ineligible (address change, refusals or death), leaving a final sample of 1,032 (95.8\%). The main demographic data on the 1,032 partici-
\end{abstract}

pants (408 men, 624 women) are provided. Conclusions: Most of the registered study population was enrolled, and this may have been due to the close relationship between NEDISA researchers and the general physicians in the area of study. The NEDISA study will likely improve our knowledge of prevalence rates of the neurological diseases chosen for study as well as the set of risk factors that predispose individuals in Spain to these disorders.

Copyright $\odot 2011$ S. Karger AG, Basel

\section{Introduction}

A series of population-based studies have been developed throughout Spain to investigate neurological disorders in the elderly [1-11]. A fundamental limitation of these studies has been the use of screening question-

The other members of the NEDISA cohort are listed in the Acknowledgments section.

\section{KARGER}

(c) 2011 S. Karger AG, Basel

Fax +41 613061234

E-Mail karger@karger.ch

www.karger.com
Accessible online at:

www.karger.com/ned
Dr. Julián Benito-León

Avenida de la Constitución 73

Portal $3,7^{\circ}$ Izquierda

ES-28821 Coslada (Spain)

E-Mail jbenitol@meditex.es 
naires to detect neurological conditions. By contrast, direct examination of all study participants would have yielded more accurate estimates of both disease prevalence and incidence and would have lessened the potential effects of diagnostic misclassification in association studies.

In 2007, we initiated a survey - Neurological Disorders in Salamanca (NEDISA) - in Salamanca, central-western Spain, in order to establish an elderly Spanish cohort among whom health status could be studied. The NEDISA study was carried out according to the rules of a population-based survey of rare diseases, in which specialists are required to make differential diagnoses in a large study sample [12]. The NEDISA study selected a cohort of elderly people living in one well-defined geographic area of Spain (central-western Spain), yet at the same time, the participants represented a range of cultural and socioeconomic backgrounds.

The main aim of this project was to analyze the prevalence rates of neurological diseases in the elderly, including stroke, dementia, mild cognitive impairment, essential tremor (ET), Parkinson's disease (PD) and restless legs syndrome. In this paper, we describe the planning and methods of the baseline survey, and report the main demographic findings of the NEDISA cohort.

\section{Methods}

\section{Geographical Area}

The site of study was the district of Los Pizarrales $(8,113$ inhabitants; $13.3 \%$ or $1,077 \geq 65$ years of age), a suburb of metropolitan Salamanca. The district includes both blue- and whitecollar populations. This site was chosen for the following reasons: (1) in the primary care setting, there was a computer-based registry of medical data on the elderly, and (2) there was a close relationship between the NEDISA researchers and local physicians and health authorities. Moreover, there were sufficient differences in social structure at this site to facilitate the study of elderly samples with different lifestyles and risk factors for neurological disease. All persons $\geq 65$ years of age were considered eligible for the study if they were resident in the area on December 31, 2006. The survey included both the household and nursing home populations of the community.

All procedures were approved by the ethical standards committees on human experimentation at Salamanca University Hospital. Written (signed) informed consent was obtained from all participants enrolled.

\section{Prevalence Date}

Point prevalence was used to measure disease frequency, and the prevalence date used was February 1, 2007. To be included in the prevalence numerator, the subject had to be alive on February 1,2007 , and disease onset had to have occurred on or before this date.

Methods and Design of the NEDISA

Baseline Survey
Study Design and Phases

Each eligible resident was invited by telephone to participate. During the telephone call, the researchers explained the scope of the study, and arranged an appointment for the evaluation. The researchers encouraged participation by informing the residents that the study evaluation would be free of charge and that there would be no discomfort. The residents were asked to bring their current medications and any relevant medical documentation with them to the evaluation. The NEDISA baseline evaluation was carried out in 2 phases.

Phase 1

In phase 1 (February 1 to May 31, 2007), a 20-min, semistructured interview was conducted, in which the following data were collected: demographic information, health status (perceived health, major chronic diseases, functional activities in daily life and medication usage), vascular risk factors and lifestyle variables (consumption of alcohol, smoking habits, etc.), as well as data on the neurological outcomes of interest (stroke, ET, PD, restless legs syndrome and cognitive disorders). Occupation was classified according to the main categories established by the Spanish National Statistics Institute, reported as the occupation the participants had been employed in for the longest period of time during their life [13].

Furthermore, all participants were examined. The neurological examination was performed by 1 of 4 senior neurologists (J.C., M.D.S., J.A. and C.R., see Acknowledgments) and 2 extensively trained general physicians (R.C. and J.d.V., see Acknowledgments) who all met at the inception of the study to establish standardized methods to perform and interpret the examination. The general neurological examination included an assessment of mental status, speech, cranial nerves, strength and tone, primary sensory modalities, reflexes, extensor toe signs, coordination and gait, as well as the motor portion of the Unified PD Rating Scale [14]. During the neurological examination, the participants were also asked to perform 3 manual tasks to assess postural and kinetic tremors including sustained bilateral arm extension, bilateral finger-nose-finger maneuver (with a minimum of 6 repetitions with each arm) and a handwriting sample. Immediately after the neurological examination, all participants underwent a brief neuropsychological test battery, implemented by experienced neuropsychologists (Y.C., S.G., L.G.-L., R.G.-G., I.C. and B.F.-C., see Acknowledgments) who were blinded to the neurological diagnosis. The test battery included tests of global cognitive performance and included the Mini-Mental State Examination $[15,16]$, the clock drawing test [17] and the Mini-Clock [18]. The Mini-Mental State Examination was performed according to Folstein et al. [15]; the examination was translated into Spanish, as previously published by a Spanish group [16]. In addition, a functional scale (the Disability Assessment for Dementia Scale) was also administered [19].

Blood samples from each participant were collected in a fasting state. We collected blood samples for apolipoprotein genotyping, complete blood count, chemistry count, sedimentation rate, vitamin $B_{12}$ and folic acid levels, thyroid function tests, syphilis serological test and homocysteine, among others.

Phase 2

In phase 2 (June 1, 2007, to June 1, 2008), all enrollees (including all those who had a neurological disease and all those who 
were healthy) were invited to the outpatient clinic at Salamanca University Hospital for a more complete neuropsychological assessment which included the Neuropsychiatric Inventory [20], the Hopkins Verbal Learning Test [21], the Dementia Rating Scale-2 [22] and the Geriatric Depression Screening Scale [23]. In addition, ability to perform activities of daily living was assessed by means of the Interview for Deterioration in Daily Living Activities [24]. These neuropsychological tests were administered and scored by 3 experienced neuropsychologists (Y.C., S.G. and L.G.-L., see Acknowledgments).

During phase 1, ET had been diagnosed using criteria that were similar those used in a Sicilian study [25]. These criteria have been used in other large-scale, population-based studies [26-39]. Thus, enrollees were diagnosed as having ET if they had an action tremor of the head or limbs without any other recognizable cause. The tremor had to be of gradual onset and either present for at least 1 year or be accompanied by a family history of the same disorder (at least 1 reported first-degree relative affected). In the handwriting sample, tremor severity had to be moderate or greater. Each patient with an ET diagnosis during phase 1 was reexamined during phase 2 using a standardized tremor examination $[40,41]$. This examination included 1 test of postural arm tremor and 5 tests of kinetic arm tremor (pouring water, drinking water, using spoon, finger-to-nose maneuver and drawing spirals) performed with each hand (12 tests in total) [40, 41].

All participants diagnosed with PD, ET or a cognitive disorder underwent structural magnetic resonance imaging using the same Vision 1.5T scanner. In addition, technetium 99m-labeled hexamethylpropyleneamine oxime single photon emission computed tomography was performed on participants with cognitive disorders. Single photon emission computed tomography imaging using $\left[{ }^{123} \mathrm{I}\right] \mathrm{FP}-\mathrm{CIT}$ (DaTSCAN; GE Healthcare) was performed on participants with ET or PD.

\section{Diagnostic Criteria}

Stroke was diagnosed based on the clinical interview, neurological examination and medical record review. The WHO clinical definition of stroke was applied: 'rapidly developing clinical signs of focal (or global) disturbance of cerebral function lasting more than 24 hours (unless interrupted by surgery or death) with no apparent cause other than a vascular origin' [42]. Stroke classification was based on the following data sources: medical records, reports of brain imaging, and the clinical judgment of the NEDISA neurologists. Stroke was classified into the following subtypes: ischemic, hemorrhagic and unknown $[43,44]$. Hemorrhagic stroke was further classified into intracerebral hemorrhage or subarachnoid hemorrhage. Extradural hematomas, subdural hematomas, traumatic hemorrhages and hemorrhages occurring with anticoagulant treatment were excluded. Ischemic stroke was diagnosed if there was clinical evidence of focal brain dysfunction and absence of intracerebral or subarachnoid hemorrhage [43, 44]. Recurrent strokes were defined as new vascular attacks that occurred more than 3 weeks after the first-ever event $[43,44]$. Transient ischemic attack (TIA) was defined as a focal neurological deficit of sudden onset occurring in a specific cerebrovascular territory and resolving without sequelae in less than $24 \mathrm{~h}$; nonvascular causes were excluded [42]. Thus, symptoms with gradual onset, positive visual or motor phenomena, 'shaking' spells, isolated diplopia or vertigo, unexplained falls, or paresthesias in the setting of hyperventilation were not classified as TIA [42]. Pa- tients with symptoms lasting less than $24 \mathrm{~h}$, but with an infarction imaged by computed tomography or magnetic resonance imaging, were reclassified as having a stroke instead of TIA. The diagnoses of stroke and TIA were considered definite if: (1) other physicians had already diagnosed stroke or TIA and the study physicians agreed, and (2) study physicians found sequelae consistent with a stroke diagnosis $[43,44]$.

For the diagnosis of dementia, we applied the Diagnostic and Statistical Manual of Mental Disorders (DSM)-IV criteria [45] and required evidence of cognitive deficit (based on either the mental state examination or neuropsychological test battery) as well as evidence of impairment of social or occupational function. If dementia was diagnosed, data on age of onset were elicited. The etiologic diagnosis of dementia included Alzheimer's disease (possible or probable Alzheimer's disease according to National Institute of Neurological and Communicative Diseases and Stroke/Alzheimer's Disease and Related Disorders Association criteria) [46], vascular dementia (DSM-IV criteria) [45] - with the Hachinski scale used only as a diagnostically supportive tool [47] -, dementia associated with PD or longstanding parkinsonism (more than 6 months) and secondary dementia (known or probable specific dementia cause). Undetermined dementia was that category for which clinical information was insufficient to reach an etiologic classification.

We applied the criteria by Petersen et al. [48] to diagnose mild cognitive impairment. These criteria were: (1) the presence of a subjective memory complaint, (2) preserved general intellectual function as estimated by performance on a vocabulary test, (3) demonstration of memory impairment by cognitive testing, (4) intact ability to perform activities of daily living, and (5) absence of dementia.

Each patient with an ET diagnosis during phase 1 was reexamined using a more detailed, standardized tremor examination [40, 41]. This examination included 1 test of postural arm tremor and 5 tests of kinetic arm tremor (pouring water, drinking water, using spoon, finger-to-nose maneuver and drawing spirals) performed with each hand (12 tests in total) [40, 41]. A senior neurologist (J.C.) used the Washington Heights-Inwood Genetic Study of Essential Tremor rating scale to rate the severity of tremor (range: 0-3 for each test) and assigned a total tremor score (range: $0-36$, i.e. a rating of 3 on 12 tests) [40, 41]. Head tremor was coded as present or absent on examination. Based on the interview and more detailed examination, diagnoses of ET were confirmed using published research criteria [40, 41], which required the presence of kinetic tremor of moderate or greater amplitude during $\geq 3$ tests, or a head tremor in the absence of other neurological disorders such as PD or dystonia [40, 41].

We defined parkinsonism based on 4 cardinal signs: resting tremor, rigidity, bradykinesia and impaired postural reflexes. Parkinsonism was diagnosed when at least 2 cardinal signs were present in a participant not receiving antiparkinsonian therapy, or when at least 1 sign was present in a participant so treated [4952]. Among participants diagnosed with parkinsonism, the following etiologic subgroups were applied:

(1) Parkinsonism related to cerebrovascular disease was defined as a form of parkinsonism with a clear time relationship between the cerebrovascular event and onset of atypical parkinsonism, preferably supported by neuroimaging, and usually without tremor [53]. 
(2) Drug-induced parkinsonism was defined as a form of parkinsonism that followed the use of antidopaminergic drugs during the preceding 6 months, along with a previously negative history for the parkinsonian signs; whenever possible, the diagnosis was confirmed if the parkinsonian symptoms disappeared 6 months after having stopped the drug.

(3) Parkinsonism with associated features or due to other etiologies (nervous system infection, severe head trauma, brain tumor, dementia or other neurological diseases that could affect the basal ganglia) was defined by routine clinical diagnosis; this type of parkinsonism also included Parkinson-plus syndromes; whether or not the patient also had dementia was determined according to DSM-IV criteria [45].

(4) Participants were diagnosed as having idiopathic PD when they met the UK Parkinson's Disease Society Brain Bank criteria [54].

(5) Unspecified parkinsonism was that for which clinical information was insufficient to reach an etiologic classification.

Finally, participants who answered 'yes' to the following 4 questions fulfilled the 4 diagnostic criteria for restless legs syndrome as established by the International Restless Legs Syndrome Study Group [55]: (1) do you ever feel like you just have to move your legs; (2) do these feelings occur mainly when you are resting; (3) do these feelings improve with movement, and (4) are these feelings worse in the evening or night than in the morning?

\section{Results}

The flow of participants is shown in figure 1 . The registered population consisted of 1,077 individuals; 45 subjects were not examined for the following reasons: participant died before phase $1(\mathrm{n}=20 ; 1.8 \%)$; participant was unreachable ( $\mathrm{n}=9 ; 0.8 \%$ ); participant refused $(\mathrm{n}=16$; $1.5 \%)$. The remaining 1,032 (95.8\%) subjects were examined. Table 1 shows the distribution of the NEDISA participants by age and gender. We obtained information about the educational level (table 2) and occupation (table 3) of 1,013 (98.2\%) and 1,027 (99.5\%) participants, respectively. Information on marital status and living arrangements was obtained from 1,027 (99.5\%) and 1,027 (99.5\%) participants, respectively (table 4 ). Data on vascular risk factors, the number of medications and number of comorbidities are shown as well (table 4 ).

\section{Discussion}

The main objective of the NEDISA study was to assess the epidemiology of stroke, cognitive disorders, ET, PD and restless legs syndrome in a single geographical area within the city of Salamanca. Our intention was to examine the majority of eligible elderly persons in Los Pizarrales, Salamanca municipality. Thus, the authorities of

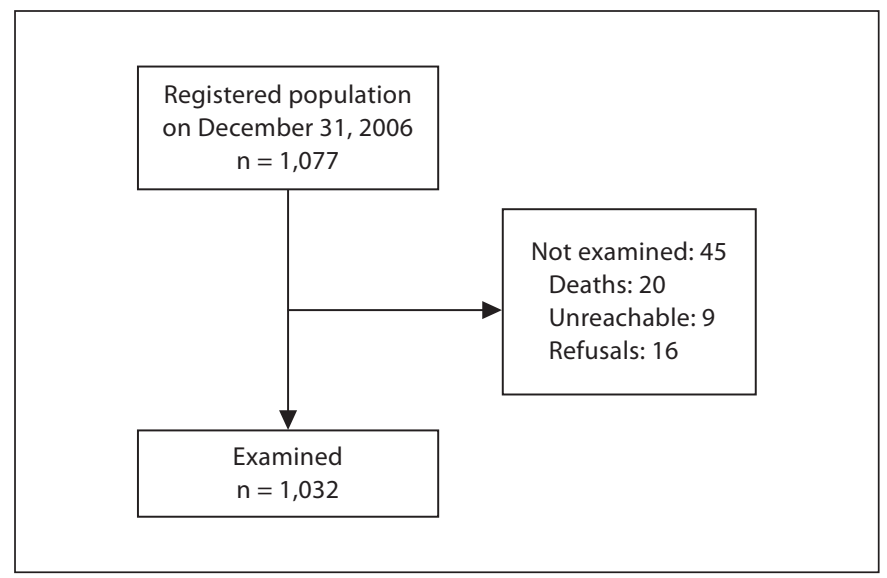

Fig. 1. Flow chart of NEDISA study population selection.

Table 1. Distribution of NEDISA participants, stratified by age group and gender

\begin{tabular}{lccc}
\hline Age, years & Men, $n$ & Women, $n$ & \multicolumn{1}{l}{ Total, $n$} \\
\hline $65-69$ & $89(21.8 \%)$ & $150(24.0 \%)$ & $239(23.2 \%)$ \\
$70-74$ & $122(29.9 \%)$ & $191(30.6 \%)$ & $313(30.3 \%)$ \\
$75-79$ & $117(28.7 \%)$ & $148(23.7 \%)$ & $265(24.7 \%)$ \\
$80-84$ & $57(14.0 \%)$ & $95(15.2 \%)$ & $152(14.7 \%)$ \\
$\geq 85$ & $23(5.6 \%)$ & $40(6.4 \%)$ & $63(6.1 \%)$ \\
\hline Total & $408(100 \%)$ & $624(100 \%)$ & $1,032(100 \%)$ \\
\hline
\end{tabular}

All percentages are column percentages.

the Salamanca municipality provided us with a computer-based list of all residents from their local registry office. This registration in Spain has important social and fiscal implications and is linked with tax filing and voting. A person may remain a resident if temporarily out of the municipality, and transfers of residence require a formal request. Health care in this area is provided by the National Health Service (NHS), and medical visits, hospitalizations and prescription medications are provided for free. Even elderly people using private medical care generally refer to National Health Service physicians to obtain free medication. Hence, we believe our ascertainment was likely to be near complete.

For the baseline visit, participation in the NEDISA study was very high (95.8\%). The very low proportion of nonparticipants may be explained by the recruiting pro- 
Table 2. Educational level of NEDISA participants by age group and gender

\begin{tabular}{|c|c|c|c|c|c|c|c|c|}
\hline \multirow[t]{2}{*}{ Age, years } & \multicolumn{2}{|c|}{$\begin{array}{l}\text { Illiterate } \\
(\mathrm{n}=24)\end{array}$} & \multicolumn{2}{|c|}{$\begin{array}{l}\text { Less than primary } \\
\text { school }(\mathrm{n}=517)\end{array}$} & \multicolumn{2}{|c|}{$\begin{array}{l}\text { Primary school } \\
(\mathrm{n}=424)\end{array}$} & \multicolumn{2}{|c|}{$\begin{array}{l}\text { Secondary school and } \\
\text { higher }(\mathrm{n}=48)\end{array}$} \\
\hline & men & women & men & women & men & women & men & women \\
\hline $65-69$ & 0 & 4 & 33 & 69 & 44 & 68 & 9 & 8 \\
\hline $70-74$ & 1 & 4 & 58 & 105 & 56 & 74 & 5 & 5 \\
\hline $75-79$ & 0 & 7 & 54 & 79 & 53 & 56 & 10 & 5 \\
\hline $80-84$ & 3 & 3 & 31 & 51 & 20 & 35 & 2 & 2 \\
\hline$\geq 85$ & 1 & 1 & 11 & 26 & 9 & 9 & 0 & 2 \\
\hline Total & 5 & 19 & 187 & 330 & 182 & 242 & 26 & 22 \\
\hline
\end{tabular}

Table 3. Occupation/employment of NEDISA participants, stratified by gender $(n=1,027)$

\begin{tabular}{lccc}
\hline & Men & Women & Total \\
\hline Housewife/husband & $9(2.2 \%)$ & $432(69.7 \%)$ & 421 \\
Unskilled worker & $245(60.2 \%)$ & $141(22.7 \%)$ & 386 \\
Skilled worker & $117(28.7 \%)$ & $28(4.5 \%)$ & 145 \\
Administrative worker & $13(3.2 \%)$ & $1(0.2 \%)$ & 14 \\
High-level technician & $7(1.7 \%)$ & $7(1.1 \%)$ & 14 \\
Medium-level technician & $7(1.7 \%)$ & $3(0.5 \%)$ & 10 \\
Other jobs & $9(2.2 \%)$ & $8(1.3 \%)$ & 17 \\
\hline
\end{tabular}

All percentages are row percentages.

cedure of the NEDISA study: a review of the census by means of official files, the comfortable environment guaranteed for the interview and medical examination, and especially the close relationship between the general physicians of the area studied and the NEDISA researchers.

The total population of this survey is obviously not representative of the whole elderly population of Spain. Despite this, the sociodemographic characteristics of the NEDISA cohort are similar to those in other Spanish studies based on elderly populations [1-11]. Taking account of the distribution of participants by education and occupation, it is probable that the NEDISA cohort is representative of a sufficient range of lifestyles, and this will allow investigators to examine a variety of different risk factors for neurological disorders. In conclusion, the NEDISA cohort will likely improve our knowledge of prevalence and incidence rates of the neurological diseases chosen for study as well as the set of risk factors that predispose individuals in Spain to these disorders.
Table 4. Demographic and general health data about NEDISA participants

\begin{tabular}{|c|c|c|}
\hline & Cases, $\mathrm{n}$ & Percentage \\
\hline \multicolumn{3}{|l|}{ Marital status } \\
\hline Single & 39 & 3.8 \\
\hline Married & 712 & 69.0 \\
\hline Separated/divorced & 21 & 2.0 \\
\hline Widowed & 255 & 24.7 \\
\hline Unknown & 5 & 0.5 \\
\hline Total & 1,032 & 100.0 \\
\hline \multicolumn{3}{|l|}{ Living arrangement } \\
\hline Alone & 206 & 20.0 \\
\hline With 1 or more persons & 708 & 68.6 \\
\hline Rotation among relatives & 69 & 6.7 \\
\hline Institutionalized & 1 & 0.1 \\
\hline Other situations & 43 & 4.2 \\
\hline Unknown & 5 & 0.5 \\
\hline Total & 1,032 & 100.0 \\
\hline \multicolumn{3}{|l|}{ Vascular risk factor } \\
\hline Ever-smoker & 131 & 12.7 \\
\hline Alcohol abuse ${ }^{1}$ & 34 & 3.3 \\
\hline Hypertension & 588 & 57.0 \\
\hline Diabetes mellitus & 158 & 15.3 \\
\hline Ischemic heart disease & 80 & 7.8 \\
\hline Number of medications & $3.25(2.25)$ & \\
\hline Number of reported diseases & $1.30(1.31)$ & \\
\hline
\end{tabular}

Numbers of medications and reported diseases are means with SD in parentheses.

${ }^{1}$ Alcoholism/alcohol abuse was defined as a disorder characterized by a pathological pattern of alcohol use that causes a serious impairment of social or occupational functioning. 


\section{Acknowledgments}

The authors gratefully acknowledge the vital help of the other members of the NEDISA Study Group: María Dolores Sevillano, Jesús Arcaya and Carmen Riveira (neurologists); Roberto Rodríguez and José de Vega (general physicians), and Yamisel Chong, Silvia Gamazo, Laura Gómez-Liz, Ricardo García-García, Israel Contador, Bernardino Fernández-Calvo and Candida Helena Lopes Alves (neuropsychologists). Finally, we also wish to express our sincere thanks to the municipal authorities, family doctors, nurses and the population of Los Pizarrales neighborhood, Sala- manca. Dr. Benito-León is supported by grant No. R01 NS039422 from the National Institutes of Health, Bethesda, Md., USA. Dr. Louis is supported by grant No. R01 NS042859 and R01 NS039422 from the National Institutes of Health.

\section{Disclosure Statement}

The authors report no conflicts of interest.

\section{References}

1 Coria F, Gomez de Caso JA, Minguez L, Rodriguez-Artalejo F, Claveria LE: Prevalence of age-associated memory impairment and dementia in a rural community. J Neurol Neurosurg Psychiatry 1993;56:973-976.

$\checkmark 2$ Matias-Guiu J, Oltra A, Falip R, Martin R, Galiano L: Occurrence of transient ischemic attacks in Alcoi: descriptive epidemiology. Neuroepidemiology 1994;13:34-39.

-3 Lobo A, Saz P, Marcos G, Día JL, de-la-Cámara C: The prevalence of dementia and depression in the elderly community in a southern European population: the Zaragoza study. Arch Gen Psychiatry 1995;52:497506.

-4 Manubens JM, Martínez-Lage JM, Lacruz F, Muruzabal J, Larumbe R, Guarch C, Urrutia T, Sarrasqueta P, Martínez-Lage P, Rocca WA: Prevalence of Alzheimer's disease and other dementing disorders in Pamplona, Spain. Neuroepidemiology 1995;14:155-164.

$\checkmark 5$ Pi J, Olivé JM, Roca J, Masana L: Prevalence of dementia in a semi-rural population of Catalunya, Spain. Neuroepidemiology 1996; 15:33-41.

6 Vilalta-Franch J, López-Pousa S, Llinàs-Reglà $\mathrm{J}$ : The prevalence of dementias in a rural area: a study in Girona (in Spanish). Rev Neurol 2000;30:1026-1032.

$\checkmark 7$ Bergareche A, de la Puente E, López de Munain A, Sarasqueta C, de Arce A, Poza JJ, Martí-Massó JF: Prevalence of essential tremor: a door-to-door survey in Bidasoa, Spain. Neuroepidemiology 2001;20:125128.

-8 Clavería LE, Duarte J, Sevillano MD, PérezSempere A, Cabezas C, Rodríguez F, de Pedro-Cuesta: Prevalence of Parkinson's disease in Cantalejo, Spain: a door-to-door survey. Mov Disord 2002;17:242-249.

9 Morales JM, Bermejo FP, Benito-León J, Rivera-Navarro J, Trincado R, Gabriel SR, Vega S, NEDICES Study Group: Methods and demographic findings of the baseline survey of the NEDICES cohort: a door-to-door survey of neurological disorders in three communities from Central Spain. Public Health 2004; 118:426-433.
10 Bermejo-Pareja F, Benito-León J, Vega-QS Díaz-Guzmán J, Rivera-Navarro J, Molina JA, Olazarán-Rodríguez J, Morales-González JM: The NEDICES cohort of the elderly: methodology and main neurological findings (in Spanish). Rev Neurol 2008;46:416-423.

11 Vega S, Benito-León J, Bermejo-Pareja F, et al: Several factors influenced attrition in a population-based elderly cohort: Neurological Disorders in Central Spain Study. J Clin Epidemiol 2010;63:215-222.

12 Anderson DW, Kalton G: Case-finding strategies for studying rare chronic diseases. Ital J Appl Stat 1990;2:309-321.

13 Instituto nacional de estadistica, clasificacion nacional de ocupaciones 1994 (CNO94). Madrid, Instituto Nacional de Estadística, 1994

14 Fahn S, Elton R, Members of the UPDRS Development Committee: Unified Parkinson's Disease Rating Scale; in Fahn S, Marsden CD, Calne DB, Goldstein M (eds): Recent Developments in Parkinson's Disease. Florham Park, Macmillan Health Care Information, 1987, vol 2, pp 153-163.

15 Folstein MF, Folstein SE, McHugh PR: 'Mini-Mental State': a practical method for grading the cognitive state of patients for the clinician. J Psychiatr Res 1975;12:189-198.

16 Blesa R, Pujol M, Aguilar M, Santacruz P, Bertran-Serra I, Hernández G, Sol JM, PeñaCasanova J, NORMACODEM Group, NORMAlisation of Cognitive and Functional Instruments for DEMentia: Clinical validity of the 'mini-mental state' for Spanish speaking communities. Neuropsychologia 2001;39: 1150-1157.

17 Cacho J, García-García R, Fernández-Calvo B, Gamazo S, Rodríguez-Pérez R, Almeida A, Contador I: Improvement pattern in the Clock Drawing Test in early Alzheimer's disease. Eur Neurol 2005;53:140-145.
18 Cacho J, Benito-León J, García-García R, Fernández-Calvo B, Vicente-Villardón JL, Mitchell AJ: Does the combination of the MMSE and Clock Drawing Test (MiniClock) improve the detection of mild $\mathrm{Alz}$ heimer's disease and mild cognitive impairment? J Alzheimers Dis 2010;22:889-896.

19 Feldman H, Sauter A, Donald A, Gélinas I, Gauthier S, Torfs K, Parys W, Mehnert A: The Disability Assessment for Dementia Scale: a 12-month study of functional ability in mild to moderate severity Alzheimer disease. Alzheimer Dis Assoc Disord 2001;15: 89-95.

20 Cummings JL, Mega M, Gray K, RosenbergThompson S, Carusi DA, Gornbein J: The Neuropsychiatric Inventory: comprehensive assessment of psychopathology in dementia. Neurology 1994;44:2308-2314.

21 Hogervorst E, Combrinck M, Lapuerta P, Rue J, Swales K, Budge M: The Hopkins Verbal Learning Test and screening for dementia. Dement Geriatr Cogn Disord 2002;13: 13-20.

$>22$ Caston JC, Diehl LA, Hedgepath AW: Utilization of the Dementia Rating Scale-2 and cognitive enhancers in the diagnosis and treatment of cognitive disorders and dementia. JSC Med Assoc 2004; 100:32-38.

$>23$ Yesavage JA, Brink TL, Rose TL, Lum O, Huang V, Adey M, Leirer VO: Development and validation of a geriatric depression screening scale: a preliminary report. J Psychiatr Res 1982-1983;17:37-49.

24 Teunisse S, Derix MM: The interview for deterioration in daily living activities in dementia: agreement between primary and secondary caregivers. Int Psychogeriatr 1997;9(suppl 1):155-162.

25 Salemi G, Savettieri G, Rocca WA, Meneghini F, Saporito V, Morgante L, Reggio A, Grigoletto F, di Perri R: Prevalence of essential tremor: a door-to-door survey in Terrasini, Sicily. Sicilian Neuro-Epidemiologic Study Group. Neurology 1994;44:61-64. 
26 Benito-León J, Bermejo-Pareja F, Morales JM, Vega S, Molina JA: Prevalence of essential tremor in three elderly populations of central Spain. Mov Disord 2003;18:389-394.

-27 Benito-León J, Bermejo-Pareja F, Louis ED, Neurological Disorders in Central Spain (NEDICES) Study Group: Incidence of essential tremor in three elderly populations of central Spain. Neurology 2005;64:17211725.

28 Benito-León J, Louis ED, Bermejo-Pareja F, Neurological Disorders in Central Spain (NEDICES) Study Group: Population-based case-control study of cognitive function in essential tremor. Neurology 2006;66:69-74.

29 Benito-León J, Louis ED, Bermejo-Pareja F, Neurological Disorders in Central Spain Study Group: Elderly-onset essential tremor is associated with dementia. Neurology 2006;66:1500-1505.

-30 Bermejo-Pareja F, Louis ED, Benito-León J, Neurological Disorders in Central Spain (NEDICES) Study Group: Risk of incident dementia in essential tremor: a populationbased study. Mov Disord 2007;22:1573-1580.

-31 Louis ED, Benito-León J, Ottman R, Bermejo-Pareja F; Neurological Disorders in Central Spain (NEDICES) Study Group: A population-based study of mortality in essential tremor. Neurology 2007;69:1982-1989.

\32 Benito-León J, Louis ED, Bermejo-Pareja F, Neurological Disorders in Central Spain (NEDICES) Study Group: Reported hearing impairment in essential tremor: a population-based case-control study. Neuroepidemiology 2007;29:213-217.

33 Benito-León J, Louis ED, Bermejo-Pareja F, Neurological Disorders in Central Spain (NEDICES) Study Group: Population-based case-control study of cigarette smoking and essential tremor. Mov Disord 2008;23:246252.

-34 Louis ED, Benito-León J, Bermejo-Pareja F, Neurological Disorders in Central Spain (NEDICES) Study Group: Population-based prospective study of cigarette smoking and risk of incident essential tremor. Neurology 2008;70:1682-1687.

>35 Louis ED, Benito-León J, Bermejo-Pareja F, Neurological Disorders in Central Spain (NEDICES) Study Group: Philadelphia Geriatric Morale Scale in essential tremor: a population-based study in three Spanish com munities. Mov Disord 2008;23:1435-1440.
36 Louis ED, Benito-León J, Bermejo-Pareja F: Population-based study of baseline ethanol consumption and risk of incident essential tremor. J Neurol Neurosurg Psychiatry 2009; 80:494-497.

37 Louis ED, Benito-León J, Bermejo-Pareja F, Neurological Disorders in Central Spain (NEDICES) Study Group: Antihypertensive agents and risk of Parkinson's disease, essential tremor and dementia: a populationbased prospective study (NEDICES). Neuroepidemiology 2009;33:286-292.

38 Louis ED, Benito-León J, Vega-Quiroga S, Bermejo-Pareja F, Neurological Disorders in Central Spain (NEDICES) Study Group: Cognitive and motor functional activity in non-demented community-dwelling essential tremor cases. J Neurol Neurosurg Psychiatry 2010;81:997-1001.

39 Louis ED, Benito-León J, Vega-Quiroga S, Bermejo-Pareja F, Neurological Disorders in Central Spain (NEDICES) Study Group: Faster rate of cognitive decline in essential tremor cases than controls: a prospective study. Eur J Neurol 2010;17:1291-1297.

40 Louis ED, Ford B, Frucht S, Barnes LF, XTang M, Ottman R: Risk of tremor and impairment from relatives of patients with essential tremor: a community-based family study. Ann Neurol 2001;49:761-769.

41 Benito-León J, Louis ED: Essential tremor: emerging views of a common disorder. Nat Clin Pract Neurol 2006;2:666-278.

42 MONICA definition. 1999. http://www.ktl fi/publications/monica/manual/part4/iv-2. htm\#s2-2 (accessed January 25, 2010).

43 Díaz-Guzmán J, Bermejo-Pareja F, BenitoLeón J, Vega S, Gabriel R, Medrano MJ, Neurological Disorders in Central Spain (NEDICES) Study Group: Prevalence of stroke and transient ischemic attack in three elderly populations of central Spain. Neuroepidemiology 2008;30:247-253.

44 Martínez-Salio A, Benito-León J, DíazGuzmán J, Bermejo-Pareja F: Cerebrovascular disease incidence in central Spain (NEDICES): a population-based prospective study. J Neurol Sci 2010;298:85-90.

45 American Psychiatric Association: Diagnostic and Statistical Manual of Mental Disorders, ed 4 (DSM-IV). Washington, American Psychiatric Association, 1994.

46 McKhann G, Drachman D, Folstein M, Katzman R, Price D, Stadlan EM: Clinical diagnosis of Alzheimer's disease: report of the NINCDS-ADRDA Work Group under the auspices of Department of Health and Human Services Task Force on Alzheimer's disease. Neurology 1984;34:939-944.
47 Hachinski VC, Lassen NA, Marshall J: Multi-infarct dementia: a cause of mental deterioration in the elderly. Lancet 1974;ii: 207-210.

-48 Petersen RC, Smith GE, Waring SC, Ivnik RJ, Kokmen E, Tangelos EG: Aging, memory, and mild cognitive impairment. Int Psychogeriatr 1997;9(suppl 1):65-69.

49 Benito-León J, Bermejo-Pareja F, Rodríguez J, Molina JA, Gabriel R, Morales JM, Neurological Disorders in Central Spain (NEDICES) Study Group: Prevalence of PD and other types of parkinsonism in three elderly populations of central Spain. Mov Disord 2003;18:267-274.

50 Benito-León J, Bermejo-Pareja F, MoralesGonzález JM, Porta-Etessam J, Trincado R, Vega S, Louis ED, Neurological Disorders in Central Spain (NEDICES) Study Group: Incidence of Parkinson disease and parkinsonism in three elderly populations of central Spain. Neurology 2004;62:734-741.

51 Benito-León J, Louis ED, Bermejo-Pareja F, Neurological Disorders in Central Spain Study Group: Population-based case-control study of morale in Parkinson's disease. Eur J Neurol 2009; 16:330-336.

52 Benito-León J, Louis ED, Bermejo-Pareja F, Neurological Disorders in Central Spain Study Group: Risk of incident Parkinson's disease and parkinsonism in essential tremor: a population-based study. J Neurol Neurosurg Psychiatry 2009;80:423-425.

53 de Lau LM, Giesbergen PC, de Rijk MC, Hofman A, Koudstaal PJ, Breteler MM: Incidence of parkinsonism and Parkinson disease in a general population: the Rotterdam Study. Neurology 2004;63:1240-1244.

-54 Hughes AJ, Daniel SE, Kilford L, Lees AJ: Accuracy of clinical diagnosis of idiopathic Parkinson's disease: a clinicopathologic study of 100 cases. J Neurol Neurosurg Psychiatry 1992;55:181-184

55 Allen RP, Picchietti D, Hening WA, Trenkwalder C, Walters AS, Montplaisi J, Restless Legs Syndrome Diagnosis and Epidemiology Workshop at the National Institutes of Health, International Restless Legs Syndrome Study Group: Restless legs syndrome: diagnostic criteria, special considerations, and epidemiology. A report from the restless legs syndrome diagnosis and epidemiology workshop at the National Institutes of Health. Sleep Med 2003;4:101-119. 